\title{
Effect of Coal Grain Size on Sorption Capacity with Respect to Propylene and Acetylene
}

\author{
Agnieszka Dudzińska ${ }^{1}$, Natalia Howaniec ${ }^{2}$ and Adam Smoliński ${ }^{2, *}$ \\ 1 Central Mining Institute, Department of Mining Aerology, Pl. Gwarków 1, 40-166 Katowice, Poland; \\ adudzinska@gig.eu \\ 2 Central Mining Institute, Department of Energy Saving and Air Protection, Pl. Gwarków 1, \\ 40-166 Katowice, Poland; n.howaniec@gig.eu \\ * Correspondence: smolin@gig.katowice.pl; Tel.: +48-32-259-2252
}

Received: 3 October 2017; Accepted: 20 November 2017; Published: 21 November 2017

\begin{abstract}
Propylene and acetylene are released to mine air with the increase in the temperature of self-heating coal. Concentrations of these gases in mine air are applied as indicators of the progress of the self-heating process. Hydrocarbons emitted from the self-ignition center are sorbed on coal, while migrating through the mine workings. Coal crushed during the mining process is characterized by a high sorption capacity, which facilitates the sorption phenomena. This results in the decrease in hydrocarbons content in mine air, and in the subsequent incorrect assessment of the development of the self-heating process. The results of the experimental study on propylene and acetylene sorption on Polish coals acquired from operating coal mines are presented in this paper. Bituminous coal is characterized by a high sorption capacity with respect to unsaturated hydrocarbons, like propylene and acetylene. The sorbed volumes depend on the grade of metamorphism, porosity, and chemical characteristics of coal. Low level of metamorphism, increased porosity, and oxygen content result in higher sorption capacity of coals. The reduction in grain size of coals also results in the increased sorption capacity with respect to hydrocarbons. The most significant increase in the volumes of sorbed propylene and acetylene with the decrease in grain class was observed for coals of low porosity, high grade of metamorphism, and low to medium sorption capacities. The 10-fold decrease in coal grain size resulted in the 3 to 6 -fold increase in the volume of sorbed propylene, and 2-fold increase for acetylene. The decrease in grain size results in higher accessibility of pore structure, increased pore volume and area, and higher number of active centers interacting with hydrocarbons of dipole characteristics. For coals with low grade metamorphism, high porosity, and high sorption capacity the volumes of sorbed propylene and acetylene increased only slightly with the decrease in coal grain size.
\end{abstract}

Keywords: coal; grain size; sorption; propylene; acetylene; self-heating

\section{Introduction}

The accumulation of heat released in the process of self-heating of coal often causes endogenous fires, creating a hazard for mining staff and serious financial losses. This is why various fire prevention activities are undertaken in mining industry to mitigate these risks [1-3]. An example of such activities is a complex control of coal's self-heating process based on the monitoring of mine air composition, which enables early detection of self-heating centers and their elimination. This method is based on the fact that the increase in the temperature with progress of the self-heating of coal results in the release of various gaseous components into mine air [4-6]. Therefore, the concentrations of selected gases in mine atmosphere enable estimation of the temperature of coal, and assessment of the progress of the process of coal self-heating. Carbon monoxide, hydrogen, and unsaturated hydrocarbons-like 
ethylene, propylene, and acetylene-may be listed among the most commonly applied indicators of the self-heating process in this method [7,8].

Gases released from the self-heating center and migrating through a mine site are sorbed on coal, which results in the decrease of their contents in mine air. This in turn causes the underestimation of the concentrations of gaseous indicators of the self-heating process and an incorrect assessment of the development of this process. The gases adsorbed on coal in the highest amounts include the unsaturated hydrocarbons-such as ethylene, propylene, and acetylene-which reduces their applicability in the assessment of the self-heating process progress [9-11]. This is particularly important in the case of coals with high sorption capacity, and with long distances between the self-heating center and the measurement point of concentrations of gaseous process indicators.

Another important factor influencing the sorption of hydrocarbons on coals is coal grain size. During the mining process, coal is crushed which affects its sorption capacity. In this paper, the analysis of the influence of coal grain size on the amounts of sorbed propylene and acetylene is presented. The aspects of the effects of grain class on the sorption capacity of coals have been previously reported in the literature for other gases. A several-fold increase in the volumes of adsorbed nitrogen and carbon monoxide with the change of grain size range from $0.500-0.700 \mathrm{~mm}$ to $0.063-0.075 \mathrm{~mm}$ has been observed [12,13]. Żyła and Kreiner [14] proved a similar trend in the study of n-hexane, cyclohexane, and benzene sorption on coals of four various grain classes: $0.12-0.15 \mathrm{~mm}, 0.09-0.12 \mathrm{~mm}, 0.06-0.09 \mathrm{~mm}$, and below $0.06 \mathrm{~mm}$. The 3 -fold increase in the amount of sorbed hydrocarbons was observed with the grain size change from $0.09-0.06 \mathrm{~mm}$ to below $0.06 \mathrm{~mm}$. The enhancement of ethane sorption for medium rank coals with a decrease in grain size has also been reported and attributed to the opening of active centers, neutralized within the structure of larger coal grains [15]. This effect resulted in the enhancement of the coal surface polarity, and consequently in larger sorption capacities with respect to ethane [15]. The influence of coal grain size on ethylene sorption has also been studied [16]. The highest increase in the sorption of ethylene has been observed for medium rank coals of low porosity and low specific surface area. A 10-fold decrease in grain size resulted in an over 3-fold increase in the volume of the sorbed ethylene. This trend was not so distinctive for lower rank coals [16]. The volumes of sorbed carbon dioxide [12], water vapor, and methanol [14] on the other hand have been reported to be less dependent on coal grain class.

\section{Materials and Methods}

Coal samples provided by seven operating coal mines of the Upper Silesian Coal Basin were selected for the study. The samples were acquired in accordance with the standard PN-G-04502:2014-1 [17], crushed in a jaw crusher, ground, sieved on Fritsch sieves to the fractions $0.500-0.700 \mathrm{~mm}, 0.125-0.250 \mathrm{~mm}$, and $0.063-0.075 \mathrm{~mm}$, and stored in nitrogen atmosphere. Chemical, technical, and petrographic analyses of coals were performed on the bases of the respective Polish standards [18-23]. The results are given in Table 1.

The BET (Brunauer-Emmett-Teller) specific surface area determined on the basis of nitrogen sorption isotherm at $77.5 \mathrm{~K}$, as well as the micropore surface area and volume determined with the application of carbon dioxide sorption at $298 \mathrm{~K}$ and DR (Dubinin-Raduszkiewicz) model were presented in Table 2. The porosity and pore volume, covering meso- and macropores, was determined with the application of mercury porosimeter Pascal 440 (CE Instruments) in the pressure range of 0.1-400 MPa for coals of a grain size range of 0.5-0.7 mm (Table 2).

The samples were outgassed under helium atmosphere, and next under vacuum at the temperature of $318 \mathrm{~K}$ to a stable residual pressure [24]. Next, the propylene and acetylene sorption measurements were performed at $298 \mathrm{~K}$ with the application of the volumetric method and ASAP 2010 analyzer (Micromeritics) in the pressure range of $0-0.1 \mathrm{MPa}$. 
Table 1. Characteristics of coal samples.

\begin{tabular}{|c|c|c|c|c|c|c|c|c|c|c|c|c|}
\hline \multirow{2}{*}{ Coal Sample } & \multirow{2}{*}{$\begin{array}{c}\text { Vitrinite } \\
\text { Reflectance, \% }\end{array}$} & \multicolumn{4}{|c|}{ Ultimate Analysis, wt.\% Daf } & \multicolumn{3}{|c|}{ Proximate Analysis, wt. $\%$, Dry } & \multicolumn{4}{|c|}{ Macerals and Minerals, vol. \% } \\
\hline & & Carbon & Hydrogen & Nitrogen & Oxygen & Moisture & Ash & Volatiles & Vitrinite & Inertinite & Liptinite & Minerals \\
\hline 1 & 0.51 & 77.69 & 4.53 & 1.17 & 15.18 & 11.11 & 14.45 & 38.14 & 67 & 28 & 5 & 11 \\
\hline 2 & 0.71 & 83.20 & 5.07 & 0.96 & 10.45 & 3.08 & 4.23 & 31.80 & 59 & 36 & 8 & 3 \\
\hline 3 & 0.70 & 84.39 & 5.29 & 1.14 & 9.01 & 3.39 & 2.65 & 37.91 & 60 & 30 & 10 & 1 \\
\hline 4 & 0.92 & 88.45 & 4.81 & 1.59 & 4.81 & 1.75 & 3.01 & 28.47 & 73 & 20 & 7 & 1 \\
\hline 5 & 1.01 & 86.89 & 4.83 & 1.27 & 6.82 & 0.60 & 8.92 & 30.87 & 91 & 8 & 1 & 4 \\
\hline 6 & 0.89 & 84.07 & 4.44 & 1.40 & 9.99 & 1.19 & 7.69 & 32.94 & 67 & 31 & 2 & 4 \\
\hline 7 & 0.78 & 84.34 & 3.99 & 1.52 & 7.49 & 1.85 & 14.18 & 35.58 & 60 & 31 & 9 & 14 \\
\hline
\end{tabular}

Table 2. Porosity and pore volume determined with the application of mercury porosimetry, specific surface area determined with the application of nitrogen sorption at $77.5 \mathrm{~K}$, and micropore surface area and volume determined with the use of carbon dioxide sorption at $298 \mathrm{~K}$ and DR model.

\begin{tabular}{|c|c|c|c|c|c|}
\hline \multirow{2}{*}{ Sample } & \multicolumn{2}{|c|}{ Pore Diameter Range: 5-7500 nm } & \multirow{2}{*}{$\mathrm{S}_{\mathrm{BET}}, \mathrm{m}^{2} / \mathrm{g}$} & \multirow{2}{*}{$S_{D-R}, m^{2} / g$} & \multirow{2}{*}{ DR Micropore Volume, $\mathrm{cm}^{3} / \mathrm{g}$} \\
\hline & Porosity, \% & Pore Volume, $\mathrm{cm}^{3} / \mathrm{g}$ & & & \\
\hline 1 & 13.55 & 0.115 & 18.95 & 170.12 & 0.068 \\
\hline 2 & 4.05 & 0.031 & 1.54 & 140.43 & 0.056 \\
\hline 3 & 3.47 & 0.028 & 0.75 & 160.51 & 0.064 \\
\hline 4 & 2.81 & 0.022 & 0.43 & 115.78 & 0.046 \\
\hline 5 & 2.39 & 0.018 & 0.36 & 120.21 & 0.048 \\
\hline 6 & 1.86 & 0.014 & 0.48 & 90.44 & 0.036 \\
\hline 7 & 2.37 & 0.018 & 0.66 & 103.18 & 0.041 \\
\hline
\end{tabular}




\section{Results}

The isotherms of propylene and acetylene sorption on coals of grain class: $0.500-0.700 \mathrm{~mm}$, $0.125-0.250 \mathrm{~mm}$, and $0.063-0.075 \mathrm{~mm}$ are presented in Figures 1 and 2, respectively.
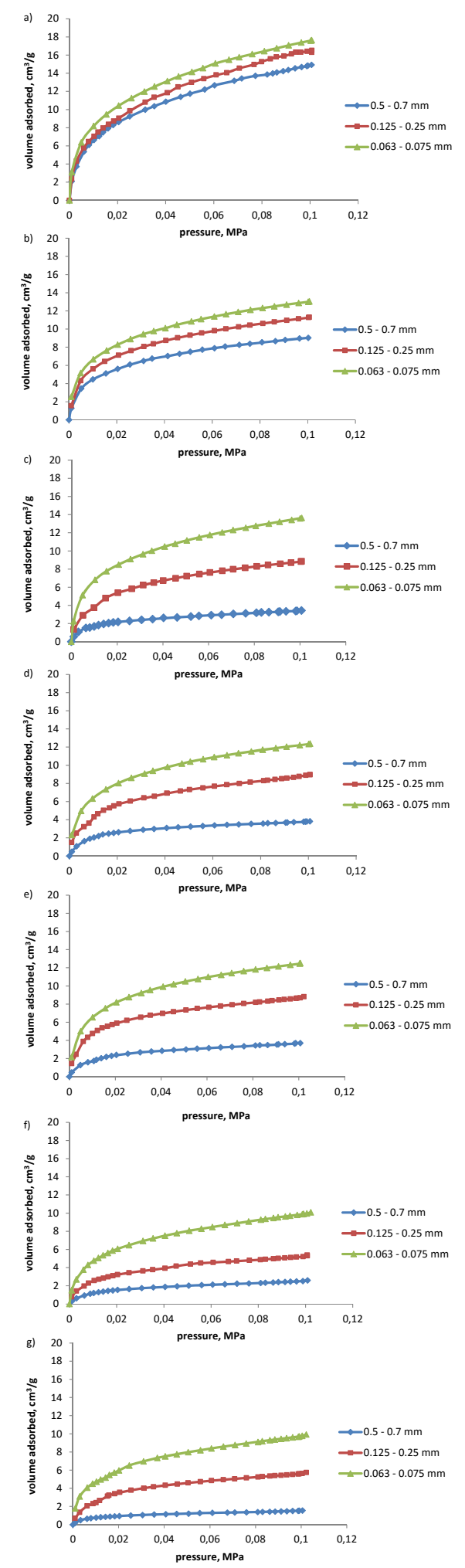

Figure 1. Isotherms of propylene sorption at $298 \mathrm{~K}$ on coal samples (a) no. 1, (b) no. 2, (c) no. 3, (d) no. 4 , (e) no. 5, (f) no. 6, and (g) no. 7 . 

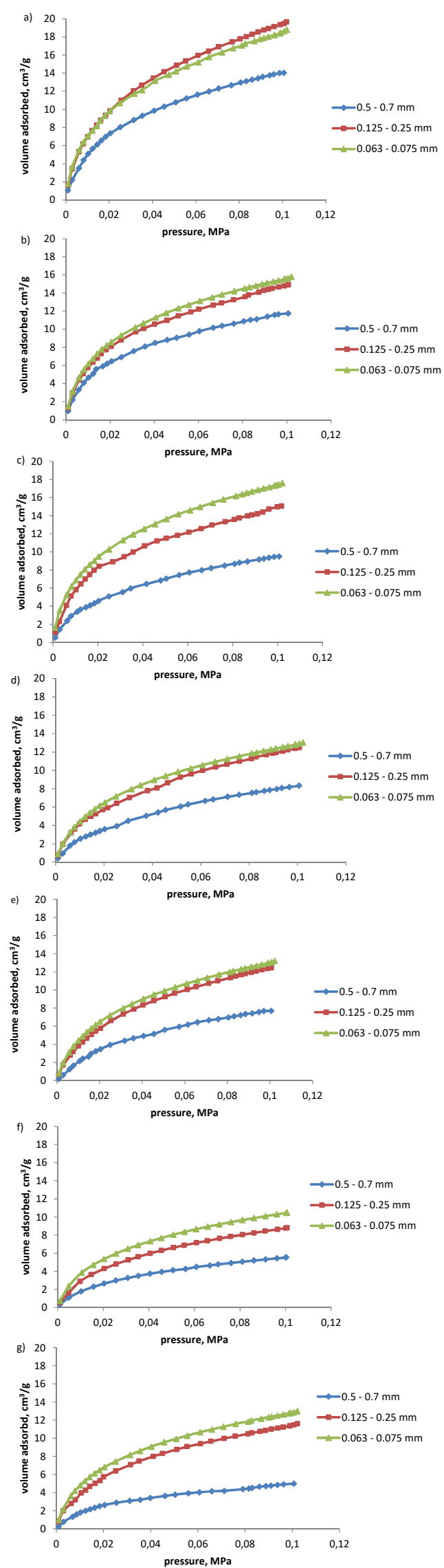

Figure 2. Isotherms of acetylene sorption at $298 \mathrm{~K}$ on coal samples (a) no. 1, (b) no. 2, (c) no. 3, (d) no. 4 , (e) no. 5, (f) no. 6, (g) and no. 7. 
The volumes of propylene and acetylene sorbed on coals of various grain classes are given in Tables 3 and 4, respectively. The highest sorption capacity with respect to propylene was observed for coal sample 1 . Approximately $25-40 \%$ less propylene was sorbed on coal sample 2 (see Table 3 ), depending on the grain size class. These two coals were characterized by the highest porosity and high specific surface area and micropore area (Table 2), as well as low grade of metamorphism and high content of oxygen (Table 1). This implies that the porous structure of these coals was relatively easily accessible for propylene molecules. The presence of reactive oxygen-containing centers on coal surface resulted in high surface polarity, and dipole-dipole interactions with propylene molecules. Considerably less propylene was sorbed on coal samples $3-5$, characterized by higher grades of metamorphism (in particularly samples 4 and 5), lower porosities, pore volumes, and oxygen contents, than coal samples 1 and 2 (see Tables 1-3). These coals were characterized by more compact structure and surface of decreased polarity in comparison with coal samples 1 and 2, which resulted in the limited accessibility of pores structure to propylene molecules. The lowest volumes of propylene were sorbed on coal samples 6 and 7, characterized by the lowest porosity and low micropore surface area (see Table 2).

Table 3. The volumes of propylene sorbed on coals of various grain class: $0.500-0.700 \mathrm{~mm}$ (V1), $0.125-0.250(\mathrm{~V} 2)$, and $0.063-0.075 \mathrm{~mm}(\mathrm{~V} 3)$ at $p=0.1 \mathrm{MPa}$ and $\mathrm{T}=298 \mathrm{~K}$.

\begin{tabular}{|c|c|c|c|c|c|c|}
\hline Sample & $\mathrm{V} 1, \mathrm{~cm}^{3} / \mathrm{g}$ & $\mathrm{V} 2, \mathrm{~cm}^{3} / \mathrm{g}$ & $\mathrm{V} 3, \mathrm{~cm}^{3} / \mathrm{g}$ & V2/V1 & V3/V2 & V3/V1 \\
\hline 1 & 14.92 & 16.52 & 17.63 & 1.1 & 1.1 & 1.2 \\
\hline 2 & 9.03 & 11.29 & 13.06 & 1.3 & 1.2 & 1.4 \\
\hline 3 & 3.44 & 8.84 & 13.64 & 2.6 & 1.5 & 4.0 \\
\hline 4 & 3.82 & 8.95 & 12.38 & 2.3 & 1.4 & 3.2 \\
\hline 5 & 3.69 & 8.68 & 12.49 & 2.4 & 1.4 & 3.4 \\
\hline 6 & 2.58 & 5.38 & 9.96 & 2.1 & 1.9 & 3.9 \\
\hline 7 & 1.55 & 5.63 & 9.78 & 3.6 & 1.7 & 6.3 \\
\hline
\end{tabular}

The grade of metamorphism [25-27], porosity, and chemical characteristics of coal surface $[10,11]$ are the most important properties of coals in terms of their sorption characteristics. The increase in the grade of metamorphism and decrease in coal porosity resulted in the deterioration of sorption capacity of tested coals with respect to propylene. The electrostatic interactions between oxygen-containing reactive centers on coal surface and $\pi$ electrons of the double bonds between carbon atoms play also a significant role in sorption of unsaturated hydrocarbons on coals $[9,10,28,29]$. Coals of higher oxygen and moisture content, and therefore of higher number of reactive oxygen-containing groups, tended to sorb higher volumes of propylene. The exception was coal sample 6, characterized by high oxygen content, but at the same time, by the lowest porosity and pore volume, resulting in low sorption capacity with respect to propylene (see Tables 1 and 3).

The total volumes of sorbed propylene decreased with the increase in grain size range for the respective coal samples tested (see Table 3 ). The increase in sorption capacity with the change in coal grain size range from $0.500-0.700 \mathrm{~mm}$ to $0.125-0.250 \mathrm{~mm}$ was denoted as a ratio V2/V1, and from $0.125-0.250 \mathrm{~mm}$ to $0.063-0.075 \mathrm{~mm}$ as a ratio V3/V2 (see Table 3). The sorption capacity of coal samples 1 and 2 increased by 10 and $30 \%$, respectively with the change of grain size range from $0.500-0.700 \mathrm{~mm}$ to $0.125-0.250 \mathrm{~mm}$. The increase in the sorption capacity with the above mentioned change of the grain size was considerably higher for coals $3-6$, and in particularly for coal sample 7 , for which the volumes sorbed on fine-grained coal were over two and over three times higher, respectively (see Table 3).

The variation in sorption capacity with the change of grain size range from $0.125-0.250 \mathrm{~mm}$ to $0.063-0.075 \mathrm{~mm}$ (V3/V2) for coals of the highest sorption capacity (coal samples 1 and 2) was similar to the one reported for V2/V1 ratio, and amounted to $10 \%$ and $20 \%$, respectively. For the remaining coal samples, the increase in the volume of propylene sorbed, with a further decrease in grain size range (V3/V2) was lower than in case of the first stage grinding (V2/V1) and amounted to $40-50 \%$ for coal samples 3-5, and 70-90\% for coal samples 6 and 7 . It was observed that the rate of the increase in 
sorption capacity with coal grain fragmentation depends on coal properties. For coals of high sorption capacity, porosity, and oxygen content, and relatively low grade of metamorphism (samples 1 and 2), the growth in the volume of propylene sorbed with coal grains fragmentation was relatively low $(10-40 \%$ ) (see Table 3).

Table 4. The volumes of acetylene sorbed on coals of various grain class: $0.500-0.700 \mathrm{~mm}$ (V1), 0.125-0.250 (V2), and 0.063-0.075 mm (V3).

\begin{tabular}{ccccccc}
\hline Sample & $\mathbf{V 1}, \mathbf{c m}^{\mathbf{3}} / \mathbf{g}$ & $\mathbf{V} \mathbf{}, \mathbf{~ c m}^{\mathbf{3}} / \mathbf{g}$ & $\mathbf{V 3}, \mathbf{c m}^{\mathbf{3}} / \mathbf{g}$ & $\mathbf{V 2 / V 1}$ & $\mathbf{V 3 / V 2}$ & $\mathbf{V 3 / V 1}$ \\
\hline 1 & 14.03 & 19.46 & 18.64 & 1.4 & 1.0 & 1.3 \\
2 & 11.98 & 14.94 & 15.64 & 1.2 & 1.0 & 1.3 \\
3 & 9.50 & 14.96 & 17.44 & 1.6 & 1.2 & 1.8 \\
4 & 8.33 & 12.52 & 12.91 & 1.5 & 1.0 & 1.5 \\
5 & 7.67 & 12.47 & 13.07 & 1.6 & 1.0 & 1.7 \\
6 & 5.56 & 8.80 & 10.49 & 1.6 & 1.2 & 1.9 \\
7 & 4.99 & 11.47 & 12.85 & 2.3 & 1.1 & 2.6 \\
\hline
\end{tabular}

Coal samples of medium sorption capacity (3-5) and coal sample 6, of more compact and ordered structure, were reported to increase the volume of propylene sorbed of about three to four times with the decrease in a grain class from $0.500-0.700 \mathrm{~mm}$ to $0.063-0.075 \mathrm{~mm}$ (V3/V1). Such a change in grain size resulted in over 6-fold increase in the volume of propylene sorbed on coal sample 7, of the lowest sorption capacity. It may be concluded that the fragmentation of coals of medium and low sorption capacity improves the accessibility of porous structure to propylene molecules and availability of active polar centers on coal surface. The fragmentation of coal results in breaking the bonds between oppositely charged active centers, which increases the surface concentration of polar sorption centers available for dipole-dipole interactions with propylene molecules $[15,28]$.

Similarly like in the case of propylene sorption, coals of lower grain class sorbed higher amounts of acetylene than coals of larger grain size range. The highest sorption capacity with respect to acetylene was characteristic for coal samples 1 and 2; medium for coal samples 3-5 and the lowest for coal samples 6 and 7 (see Table 4).

The amounts of sorbed acetylene were in general higher than those of propylene for the respective coals tested. The volumes of acetylene sorbed on coal samples $3-7$ of a grain size range $0.500-0.700 \mathrm{~mm}$ were from two to three times higher than the amounts of propylene sorbed. Coal sample 2, of the largest grain class tested, sorbed approximately 30\% more acetylene than propylene, and for coal sample 1 these values were comparable (see Tables 3 and 4). Such a trend was less pronounced for coals of grain size fractions $0.125-0.250 \mathrm{~mm}$ and $0.063-0.075 \mathrm{~mm}$.

\section{Discussion}

The higher sorption of acetylene than of propylene is related to its molecular structure. The triple bond between carbon atoms in a molecule of acetylene makes the weak $\pi$ bonds accessible for interactions at electron-donor and electron-acceptor centers of coal surface. Furthermore, the molecular diameters of propylene and acetylene are $0.39 \mathrm{~nm}$ and $0.33 \mathrm{~nm}$, respectively, which also affects the accessibility of coal micropore structure to the molecules of hydrocarbons discussed.

The volumes of sorbed acetylene increased with coal grains fragmentation of $20-60 \%$ with the change in coal grain diameters from $0.500-0.700 \mathrm{~mm}$ to $0.125-0.250 \mathrm{~mm}$ (V2/V1) for all coal samples except for coal sample 7, for which the value doubled with the reduction in coal size class (see Table 4). The reduction in the coal grain diameter range from $0.125-0.250 \mathrm{~mm}$ to $0.063-0.075 \mathrm{~mm}(\mathrm{~V} 3 / \mathrm{V} 2)$ resulted in only a slight further increase in the amount of acetylene sorbed and reported only for three coal samples: $10 \%$ for sample 7 , and $20 \%$ for samples 3 and 6 . The increase in sorption capacity with respect to acetylene with the coal grain size reduction from $0.500-0.700 \mathrm{~mm}$ to $0.063-0.075 \mathrm{~mm}$ (V3/V1) 
amounted to $30-80 \%$ for the majority of coals tested (samples 1-5). For coal samples of the lowest sorption capacity this increase was higher, of 90-160\% (coal samples 6 and 7, respectively).

It was also observed that the increase in the volume of hydrocarbons sorbed with the fragmentation of coal grains was more considerable in case of propylene sorption, than of acetylene sorption for coal samples 3-7, of medium and low sorption capacity (see Tables 3 and 4). For coals 1 and 2, the grain size-dependent change in sorption capacity with respect to hydrocarbons selected-was low and comparable for both propylene and acetylene.

It may be therefore concluded that coal fragmentation results in the increase in sorption capacity, in particular with respect to propylene, and especially for coals of high grade of metamorphism, adsorbing low and medium amounts of hydrocarbons. For such coals, the increase in volumes adsorbed of even a few-fold was observed with coal fragmentation. Coals of vitrinite reflectance of approximately $0.9 \%$ are reported to be more susceptible to crushing than coals of lower grade of metamorphism $[30,31]$. This implies that coals of high grade of metamorphism are easily fragmented during mine operation, and the enhanced sorption of hydrocarbons may take place. The application of the self-heating process assessment method based on concentrations of selected gases in mine air may be therefore arguable under such conditions. In particular, the application of the indicators based on the relationship between the propylene and acetylene content in mine air, assumedly increasing with the increase in the temperature of self-heating coal, may be misleading [4,32]. The increased sorption of gas indicators on fragmented coals results in the reduction of their concentration in mine air, underestimation of their content in the self-heating center, and the subsequent incorrect assessment of the self-heating process development.

\section{Conclusions}

1. The sorption capacity of coals with respect to propylene and acetylene depends on the grade of metamorphism, porosity, and chemical properties of coals. Coals of lower grade of metamorphism, high porosity, and high oxygen content tend to sorb higher volumes of the hydrocarbons discussed.

2. Coals characterized by low or medium porosity and sorption capacity and high grade of metamorphism sorbed up to a few-fold higher volumes of acetylene than propylene. The difference in the volumes of propylene and acetylene sorbed was not so pronounced for coals of high sorption capacity. Higher amounts of acetylene sorbed result from its higher reactivity (triple bond between carbon atoms) and small kinetic diameter.

3. The fragmentation of coal results in the increase in the amounts of propylene and acetylene sorbed, particularly noticeable for coals of higher grade of metamorphism, and low or medium sorption capacity. For such coals the increase of 3 to 6 -fold in the volume of propylene sorbed with fragmentation of coal was observed, and of up to over 2-fold for acetylene. The structure of coals with a low degree of metamorphism is easily accessible for the molecules of hydrocarbons irrespective of coal grain size. The reduction in coal grain class results in the increase in its sorption capacity, and number of active centers on its surface. The highest increase in sorption capacity was observed with the change in the grain size range from $0.500-0.700 \mathrm{~mm}$ to $0.125-0.250 \mathrm{~mm}$.

4. The enhanced sorption of selected hydrocarbons, particularly with propylene, on fragmented coals may result in the underestimation of their contents in the self-ignition center and in the subsequent incorrect assessment of the development of the self-heating process. This makes the method of assessment of the development of the self-heating process based on the measurement of propylene and acetylene contents in mine air less suitable for coals of higher grades of metamorphism, in particular those susceptible to crushing.

Acknowledgments: This work was supported by the Ministry of Science and Higher Education, Poland [11100117]. Author Contributions: A.D. performed the experiments; A.D., A.S. and N.H. analyzed the data and wrote the paper. 
Conflicts of Interest: The authors declare no conflict of interest. The founding sponsors had no role in the design of the study; in the collection, analyses, or interpretation of data; in the writing of the manuscript, and in the decision to publish the results.

\section{References}

1. Dai, G.L. Study on the gaseous products in coal oxidation at low temperature. Coal-Mine Safe 2007, 1, 1-4.

2. Singh, A.K.; Singh, R.V.K.; Singh, M.P.; Chandra, H.; Shukla, N.K. Mine fire gas indices and their application to Indian underground coal mine fires. Int. J. Coal Geol. 2007, 69, 192-204. [CrossRef]

3. Smith, M.; Glasser, D. Spontaneous combustion of carbonaceous stockpiles. Part I: The relative importance of various intrinsic coal properties and properties of the reaction system. Fuel 2005, 84, 1151-1160. [CrossRef]

4. Adamus, A.; Sancer, J.; Guranova, P.; Zubicek, V. An investigation of the factors associated with interpretation of mine atmosphere for spontaneous combustion in coal mines. Fuel Process. Technol. 2011, 92, 663-670. [CrossRef]

5. Lu, P.; Liao, G.X.; Sun, J.H.; Li, P.D. Experimental research on index gas of the coal spontaneous at low-temperature stage. J. Loss Prev. Proc. 2004, 17, 243-247. [CrossRef]

6. Taraba, B.; Pavelek, Z. Study of coal oxidation behavior in re-opened sealed heating. J. Loss Prev. Proc. 2016, 40, 433-436. [CrossRef]

7. Xie, J.; Xue, S.; Cheng, W.; Wang, G. Early detection of spontaneous combustion of coal in underground coal mines with development of an ethylene enriching system. Int. J. Coal Geol. 2011, 85, 123-127. [CrossRef]

8. Yuan, L.; Smith, A.C. $\mathrm{CO}$ and $\mathrm{CO}_{2}$ emissions from spontaneous heating of coal under different ventilation rates. Int. J. Coal Geol. 2011, 88, 24-30. [CrossRef]

9. Dudzińska, A. Investigation of adsorption and desorption of acetylene on hard coal samples from Polish mines. Int. J. Coal Geol. 2014, 128-129, 24-31. [CrossRef]

10. Dudzińska, A.; Howaniec, N.; Smoliński, A. Experimental study on sorption and desorption of propylene on Polish hard coals. Energy Fuel 2015, 29, 4850-4854. [CrossRef]

11. Dudzińska, A.; Cygankiewicz, J. Analysis of adsorption tests of gases emitted in the coal self-heating process. Fuel Process. Technol. 2015, 137, 109-116. [CrossRef]

12. Cygankiewicz, J.; Dudzińska, A.; Żyła, M. The effect of particle size of comminuted bituminous coal on low-temperature sorption of nitrogen and room temperature sorption of carbon dioxide. Przem. Chem. 2006, 85, 1505-1509.

13. Cygankiewicz, J.; Dudzińska, A.; Żyła, M. The relation between the size of bituminous coal particles and the sorption of carbon monoxide. Gospod. Surowcami Miner. 2009, 25, 85-100.

14. Żyła, M.; Kreiner, K. The effect of hard coal comminution on the sorption of vapours of polar and apolar substances. Arch. Min. Sci. 1993, 38, 41-50.

15. Żyła, M.; Dudzińska, A.; Cygankiewicz, J. The influence of disintegration of hard coal varieties of different metamorphism grade on the amount of absorbed ethane. Arch. Min. Sci. 2013, 58, 449-463.

16. Dudzińska, A. Examination of adsorption and desorption of ethylene on several samples of Polish hard coals. In Proceedings of the 14th International Multidisciplinary Scientific GeoConference on Science and Technologies in Geology, Exploration and Mining, Albena, Bulgaria, 17-26 June 2014.

17. Polish Committee for Standardization (PCS). PN-G-04502:2014-11 Hard Coal and Lignite. Sampling and Preparation for Laboratory Tests. Basic Methods; Polish Committee for Standardization: Warsaw, Poland, 2014.

18. Polish Committee for Standardization (PCS). PN-G-04571:1998 Solid Fuels. Determination of C, H, and N Content with Automatic Analyzers. Macro Method; Polish Committee for Standardization: Warsaw, Poland, 1998.

19. Polish Committee for Standardization (PCS). PN-G-04560:1998 Solid Fuels. Determination of Moisture, Volatiles and Ash with the Application of Automatic Analyzer; Polish Committee for Standardization: Warsaw, Poland, 1998.

20. Polish Committee for Standardization (PCS). PN-G-04516:1998 Solid Fuels. Determinations of Volatiles with Gravimetric Method; Polish Committee for Standardization: Warsaw, Poland, 1998.

21. Polish Committee for Standardization (PCS). PN-G-04584:2001 Solid Fuels. Determination of Total Sulfur and Ash Sulphur with the Application of Automatic Analyzers; Polish Committee for Standardization: Warsaw, Poland, 2001. 
22. Polish Committee for Standardization (PCS). PN-ISO 7404-3:2001 Methods of Petrographic Analysis of Bituminous Coal and Anthracite. Method of Determination of Maceral Groups; Polish Committee for Standardization: Warsaw, Poland, 2001.

23. Polish Committee for Standardization (PCS). PN-ISO 7404-5:2002 Methods of Petrographic Analysis of Bituminous Coal and Anthracite. Part 5: Microscopic Method; Polish Committee for Standardization: Warsaw, Poland, 2002.

24. Saha, S.; Sharma, B.K.; Kumar, S.; Sahu, G.; Badhe, Y.P.; Tambe, S.S.; Kulkarni, B.D. Density measurements of coal samples by different probe gases and their interaction. Fuel 2007, 86, 1594-1600. [CrossRef]

25. Chalmers, G.R.L.; Bustin, R.M. On the effects of petrographic composition on coalbed methane sorption. Int. J. Coal Geol. 2006, 69, 288-304. [CrossRef]

26. Karacan, C.O.; Mitchell, G.D. Behaviour and effect of different coal microlithotypes during gas transport or carbon dioxide sequestration into coal seams. Int. J. Coal Geol. 2003, 53, 201-217. [CrossRef]

27. Ozdemir, E.; Morsi, B.I.; Schroeder, $\mathrm{K} \mathrm{CO}_{2}$ adsorption capacity of argonne premium coals. Fuel 2004, 83, 1085-1094. [CrossRef]

28. Dudzińska, A.; Żyła, M.; Cygankiewicz, J. Effect of disintegration of bituminous coal on the amount of sorbed ethane. Przem. Chem. 2014, 93, 206-211.

29. Krzyżanowski, A.; Zarębska, K. The unpolar liquid vapour sorption on coal with various petrographic compositions. Gospod. Surowcami Miner. 2007, 23, 175-181.

30. Hansen, A.E.; Hower, J.C. Notes on the relationship between microlithotype composition and Hardgrove grindability index for rank suites of Eastern Kentucky (Central Appalachian) coals. Int. J. Coal Geol. 2014, 131, 109-112. [CrossRef]

31. Trimble, A.S.; Hower, J.C. Studies of the relationship between coal petrology and grinding properties. Int. J. Coal Geol. 2003, 54, 253-260. [CrossRef]

32. Cygankiewicz, J. About determination of susceptibility of coals to spontaneous combustion using an adiabatic test method. Arch. Min. Sci. 2000, 45, 247-273.

(C) 2017 by the authors. Licensee MDPI, Basel, Switzerland. This article is an open access article distributed under the terms and conditions of the Creative Commons Attribution (CC BY) license (http://creativecommons.org/licenses/by/4.0/). 